\title{
Mbeki gives AIDS scientists the cold shoulder
}

\section{Michael Cherry, Durban}

South African President Thabo Mbeki has answered critics of his stance on the relationship between HIV and AIDS by ignoring them. Opening the 13th international AIDS conference in Durban last Sunday, he made no reference to an appeal from scientists to revise his position (see Nature 406, 15-16; 2000).

Mbeki has generated widespread concern by refusing to endorse the view that HIV causes AIDS. His decision to stick to this position - although he did refer to "HIV/AIDS" in his speech - disappointed many delegates. They were also frustrated by the lack of any mention of how Mbeki's government hopes to reduce the transmission of HIV from pregnant women to their babies.

"I'm disappointed that an opportunity was lost, both to set the record straight on the causation of AIDS, and to present a concrete plan to reduce mother-to-child transmission," says Slim Karim, head of the HIV/AIDS unit at the South African Medical Research Council (MRC).

"Mbeki waffles on, while Rome burns," says paediatrician Glenda Gray, director of the perinatal HIV/AIDS unit at Chris Hani Baragwanath Hospital in Johannesburg.

Mbeki focused on the well-documented impact of poverty on AIDS. "What he said is accurate; it's just what he didn't say that is the issue," says Lynne Mofenson of the National Institute of Child Health and Development at the US National Institutes of Health. But she adds a hope that, "as he gains more insight, he will recognize that perinatal transmission is something that can be prevented, and hopefully act accordingly".

Mbeki said his advisory panel on AIDS, which met for the second time last week (see Nature 406, 3; 2000), had agreed to report back by the end of the year on "the reliability of and the information communicated by our current HIV tests and the improvement of our disease surveillance system".

The panel has been sharply split between those who accept the HIV hypothesis and the 'dissidents', led by Peter Duesberg of the University of California, who challenge it.

The meeting hammered out a broad proposal to test the accuracy of HIV testing in South Africa by comparing the results of ELISA (enzyme-linked immunosorbent assay) tests for HIV with those of other HIV tests, including the isolation of the virus.

MRC president Malegapuru Makgoba presented evidence to the panel that the percentages of false positives - the concern of the dissidents - and false negatives recorded in South African laboratories were similar to those in Western countries. Despite this, the panel agreed to test the accuracy of ELISA "in the interests of keeping the peace", according

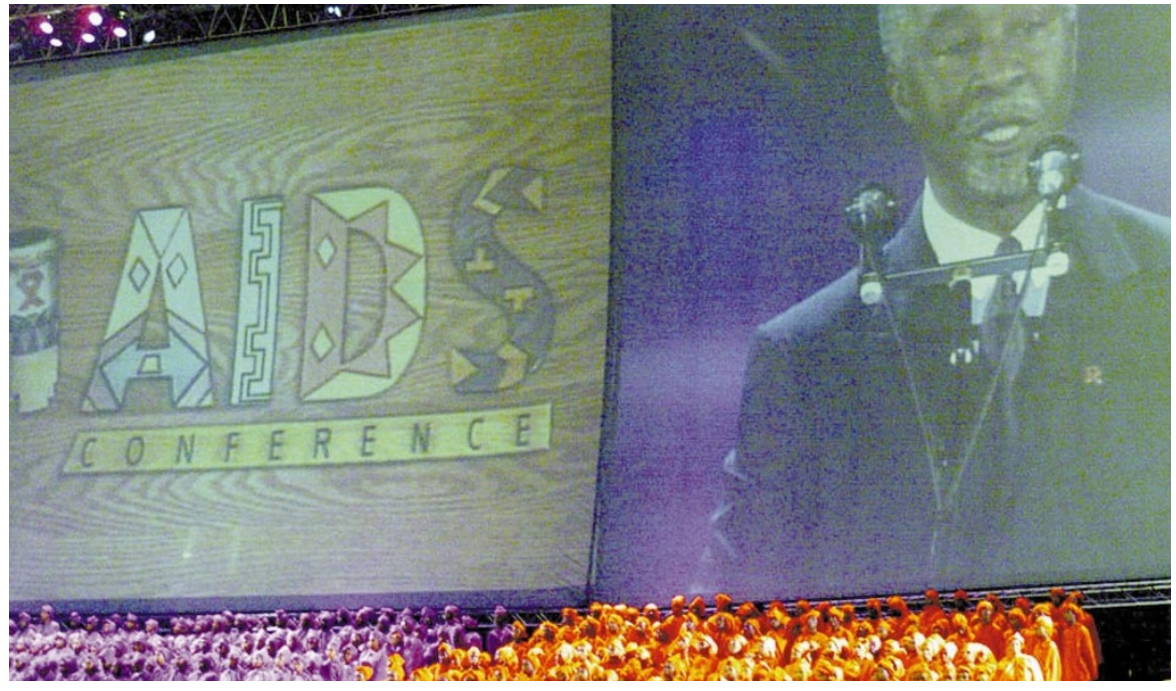

Don't turn away: President Mbeki addressed the Durban conference on its opening day.

to Karim, one of its members.

Khotso Mokhele, president of the National Research Foundation and head of the panel's secretariat, said after the meeting that he hoped the testing of screening procedures might persuade one side to "shut up once and for all". But observers say dissidents and orthodox members are unlikely to agree on what isolation of the virus actually means.

South African HIV statistics are based on antenatal surveys analysed at laboratories across the country, using a standard protocol. Researchers would like to see testing centralized, eliminating the marginally differing levels of false negatives and positives recorded. Although panel members agree this is desirable, it would be unlikely to significantly alter estimates of HIV prevalence.

Mbeki referred in his conference speech to the need for accurate statistics rather than "estimates based on projections" — another of the dissidents' arguments - but ignored statistics on changes in mortality obtained from data compiled by his own Department of Home Affairs.

These show that deaths in South Africa among men in the 15-49 age group have increased during the past decade from $48 \%$ to $87 \%$, while those for women in this age group have risen from $27 \%$ to $68 \%$.

Although Mbeki did not mention the issue, mother-to-child transmission of HIV seemed set to dominate the conference. Several South African studies were presented which showed that the antiretroviral drugs AZT and nevirapine are roughly similarly effective in preventing mother-to-child transmission, even though nevirapine is only a fraction of the cost of AZT.

One outstanding issue being used by the South African government to justify not supplying either drug to pregnant women is the possibility of subsequent transmission via breastfeeding. But new evidence being presented at the conference suggests that this can be significantly reduced by early weaning, where formula feeding is possible.

http://www.aids2000.com

\section{UK studentships get funding boost}

\section{Natasha Loder, London}

The basic annual award of British research students is set to rise by 23 per cent in real terms over the next three years. The deal means that over five years the minimum government research studentship will have risen from $\mathfrak{E} 5,500$ (US\$8,300) to $\mathfrak{E 9 , 0 0 0}$ a year.

The UK Treasury announced the news last week together with a two-year, $\mathfrak{E} 1$ billion package of investment in buildings,

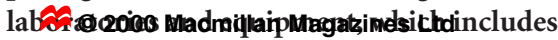

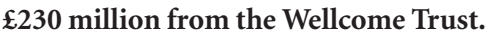

In recent years, both industry and academia have expressed concern over the quality of research students. Extra money has helped: in 1998, following an increase of $\mathfrak{E} 1,000$, the number of unfilled studentships at the Engineering and Physical Sciences Research Council halved (see Nature 401, 519; 1999).

But a study commissioned last year by the Office of Science and Technology showed that undergraduate debt had a significant impact on the supply of research students, and revealed a shortage of $\mathrm{PhD}$ candidates 
$\Xi$

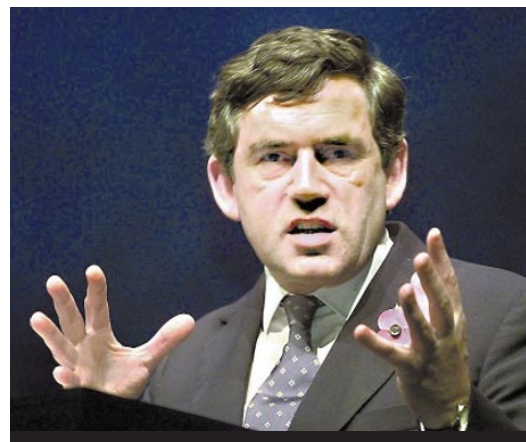

Brown: plans to increase funding, but some fear a cut in the number of studentships.

in many areas, including the biological and physical sciences.

The government has not yet said how much extra money will be available to cover the increases, leading some to fear that student numbers could fall. Earlier this year the life-science community called for a pay increase, even if it meant cutting back on numbers (see Nature 403, 347; 2000). But the Treasury has denied that this is their intention. A spokesperson said the aim was to have more and better research students, and that "this does not mean fewer studentships".

Bob Price, the head of human and corporate resources at the Biotechnology and Biological Sciences Research Council (BBSRC), welcomed the announcement with "open arms" and expects it to raise the quality and quantity of research students.

But earlier this year John Taylor, the director-general of the research councils, decided that stipends did not have to be harmonized, and that individual councils could choose whatever level they thought appropriate. Accordingly, the BBSRC's minimum went up to $\mathfrak{E 7 , 3 8 0}$ and is under review. Price says it could increase beyond the amount announced by the Treasury, but that this would "need a reduction in the number of places".

But although welcoming the money in principle, many scientists are reserving judgement until the small print is revealed later this month particularly as the announcements appeared as a leak to two newspapers of a speech by Gordon Brown, the Chancellor of the Exchequer, and as selective details released by the Treasury.

Indeed, science may not be a net beneficiary. Money could be redistributed from other budgets, as was the case with government departmental spending (see Nature 404, 909; 2000), or clawed back elsewhere. The full results will be known when the government releases details of the Comprehensive spending Review in a few weeks.

\section{Tangled tale of a lost, stolen and disputed coelacanth}

Heather McCabe, Paris \& Janet Wright, London Strange stories have long circulated around the coelacanth, the 'living fossil' fish discovered off the coast of South Africa in the 1930s.

The latest are claims by French researchers who say they were the first scientists to find the Indonesian variety, in 1995. But the photograph they sent to Nature to support their claims has been denounced by another researcher as a fake.

Until recently, coelacanths had only been found on the west side of the Indian Ocean. The first recorded Indonesian sample was discovered by a US biologist, Mark Erdmann of the University of California at Berkeley, who published news of his find in Nature (see Nature 395, 335; 1998).

In a recent submission to Nature, the French team - Bernard Séret, Laurent Pouyaud and Georges Serre - say they were unable to register their specimen in 1995 because it failed to reach the museum to which it had been sent. They say Serre photographed the fish at the time, then lost the picture (their only other evidence) while moving house, and only found it again this year.

But Nature staff noticed that the fish in the new photograph appears virtually identical to the one caught by Erdmann. When contacted, Roy Caldwell, a co-author of the 1998 paper, scrutinized the photograph via a picture-editing computer program and said, "I am $100 \%$ certain the image is a fake".

When Erdmann spotted a coelacanth off the northeast coast of Sulawesi in 1998, his find expanded the geographical distribution of the fish by roughly $10,000 \mathrm{~km}$. But Georges Serre, a consultant for what is now the French Institut de Recherche pour le Développe-

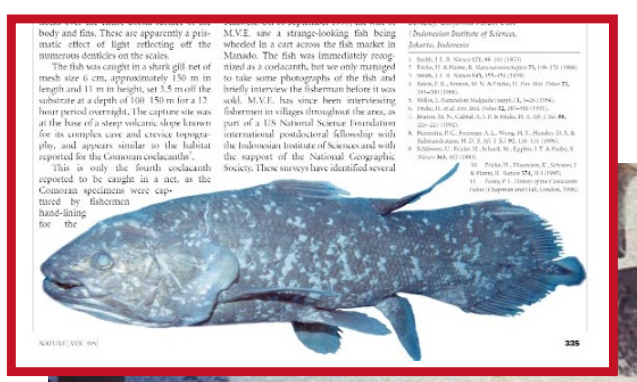

ment (IRD), has long claimed that a $10-\mathrm{kg}$ specimen was caught in 1995 in the Bay of Pangandaran, in Southwest Java.

Serre says he gave the specimen to a fisherman to hand over to the Indonesian fishery service. But the man gave it to a museum, from which it was stolen. Only recently, according to Serre, did Pouyaud, an IRD geneticist in Jakarta, track down the coelacanth to a private collection, whose owner refuses access to the fish.

The French team's finding, if confirmed, would further extend the distribution of this elusive creature, as it was caught more than 2,000 $\mathrm{km}$ from the spot where Erdmann found his 1998 specimen, suggesting a large distribution in the Indo-West Pacific region.

The whole issue is already shrouded in controversy. After analysing the specimen that Erdmann had given to the Indonesian authorities, Pouyaud and his colleagues at the Indonesian Institute of Science named it as a distinct species, Latimeria menadoensis - to the chagrin of Erdmann, who had been analysing tissue samples independently.

Caldwell says that coelacanths have highly individual spot patterns; the pattern in the two photographs is virtually identical. The bulky fish in the 1998 photo was swimming in the sea, yet is seen in the identical position, in the new photo, while lying on a slab. Shadows and other details seen when the image is magnified add to Caldwell's impression that the new photograph has been manipulated.

Serre still claims that the photograph is authentic, though he now says it was taken by a friend who later died and whose widow gave it to Serre before moving abroad.

Séret, who is an ichthyologist at the Muséum National d'Histoire Naturelle de Paris, admits that the two photographs do appear to show the same fish. "This is very embarrassing," he says. 